\title{
Reduction of bend scour with an air-bubble screen - morphology and flow patterns
}

\author{
Violaine DUGUÉ ${ }^{1}$, Koen BLANCKAERT ${ }^{1,2}$, Qiuwen CHEN $^{3}$, and Anton J. SCHLEISS ${ }^{4}$
}

\begin{abstract}
The interplay between streamwise flow, curvature-induced secondary flow, sediment transport and bed morphology leads to the formation of a typical bar-pool bed morphology in open-channel bends. The associated scour at the outer bank and deposition at the inner bank may endanger the outer bank's stability or reduce the navigable width of the channel. Previous preliminary laboratory experiments in a sharply curved flume with a fixed horizontal bed have shown that a bubble screen located near the outer bank can generate an additional secondary flow located between the outer bank and the curvature-induced secondary flow and with a sense of rotation opposite to the latter. This bubble-induced secondary flow redistributes velocities and bed shear stresses. The reported study investigates the implications of a bubble screen on the flow and the morphology in configurations with mobile bed. Velocity measurements show that the bubble-induced secondary flow shifts the curvature-induced secondary flow in inwards direction and reduces its strength. The bubble screen considerably reduces morphological gradients. Maximum bend scour is reduced by about $50 \%$ and occurs further away from the outer bank where it does not endanger the bank stability anymore. The location of maximum scour coincides with the junction of the curvature-induced and bubble-induced secondary flows. At this same location, the maximum streamwise velocities and maximum vertical velocities impinging on the bed also occur, which indicates their importance with respect to the formation of bend scour. The bubble screen also substantially reduced deposition at the inner bank. These preliminary experiments show the potential of a bubble screen to influence and modify the bed morphology.
\end{abstract}

Key Words: Bubble screen, Erosion, Scour, Morphodynamics, Open-channel bend

\section{Introduction}

Low-gradient rivers often develop a meandering morphology, whereby each individual bend of the meander is characterized by a particular morphological profile. Outer banks are vulnerable to scouring, whereas deposition occurs near the inner bank. This so-called bar-pool morphology is related to the existence of a curvature-induced secondary flow, where secondary flow is defined as flow perpendicular to the streamwise axis. This secondary flow redistributes the velocities and the boundary shear stresses, and hence also the sediment transport and the morphology (Rozovskii, 1957; Blanckaert and de Vriend, 2003, 2004, 2010; Blanckaert and Graf, 2004).

The formation of the typical bar-pool morphology in open-channel bends leads to adverse impacts, such as increased risk of erosion at the outer bank or reduced navigable width. Several techniques exist to reduce these adverse impacts, but they generally imply substantial constructive works. Techniques reported in literature include bottom vanes (Odgaard and Spoljaric, 1986; Odgaard and Wang, 1991), fixed layers (Roca et al., 2007), submerged groynes (Przedwojski, 1995) and bandal-like structures (Teraguchi et al., 2011). However, these techniques have the disadvantage of being fixed constructions on the bed that represent a possible threat for navigation. This paper describes an innovative technique that consists in indirectly manipulating the morphology by provoking changes in the flow pattern.

Previous preliminary laboratory experiments in a sharply curved flume with a fixed horizontal bed have shown that a bubble screen, which originates from a porous tube located on the bed near the outer bank, can generate an additional secondary flow located between the outer bank and the curvature-induced secondary flow and with a sense of rotation opposite to the latter (Blanckaert et al., 2008). In these previous preliminary experiments, the additional bubble-induced

${ }^{1}$ Ph.D. Student, ${ }^{4}$ Prof., Ecole Polytechnique Fédérale de Lausanne (EPFL), Laboratory of Hydraulic Constructions (LCH), Station 18, CH-1015 Lausanne, Switzerland. Corresponding author, E-mail: violaine.dugue@epfl.ch

2 Dr., ${ }^{3}$ Prof., State Key, Laboratory of Urban and Regional Ecology, Research Center for Eco-Environmental Sciences, Chinese Academy of Sciences, Beijing, China

Note: The original manuscript of this paper was received in Mar. 2012. The revised version was received in Dec. 2012. Discussion open until Mar. 2014. 
secondary flow was efficient in redistributing velocities and boundary shear stresses. The cores of maximum descending vertical velocities and of maximum streamwise velocities, which are assumed to play an important role with respect to the development of the bend scour, were shifted away from the outer bank and situated at the junction of both secondary flows.

Contrary to "hard" engineering techniques, bubble screens have the advantage of being controllable, ecological (oxygenation), reversible and non-permanent. Bubble plumes and screens have already been applied in a wide range of applications, such as aeration and destratification of lakes and reservoirs (Schladow, 1992; Wüest et al., 1992), or venting of aerosol mixtures into water pools in nuclear power plants (Smith, 1998). However, bubble screens have not yet been investigated or applied in shallow river morphodynamics.

Following the promising results of the previous preliminary study over a fixed horizontal bed (Blanckaert et al., 2008), similar experiments with mobile bed have been performed with and without the bubble screen in order to understand its influence on the interplay between the morphology and the flow field. Morphologic and hydrodynamic comparisons are provided in this paper with the aim to answer the following questions:

- Can the bubble screen technique be applied to manipulate the morphology in open-channel bends ?

- How does the bubble-induced secondary flow redistribute the velocities and the morphology?

This paper briefly describes the laboratory flume and the experimental conditions, presents the results for the reference and bubble-screen experiments and discusses the impact of the bubble screen on the morphology and hydrodynamics of the bend.

\section{Experiments and measurement techniques}

\subsection{Experimental set-up}

Experiments were performed in a sharply curved laboratory flume (Fig. 1a) at the Ecole Polytechnique Fédérale de Lausanne (EPFL) in Switzerland. This flume has vertical PVC sidewalls and a width that is constant at $B=1.3 \mathrm{~m}$. From upstream to downstream, the flume consists of a $9 \mathrm{~m}$ long straight inflow reach, a $193^{\circ}$ bend with centerline radius of curvature $R=1.7 \mathrm{~m}$, and a $5 \mathrm{~m}$ long straight outflow reach which includes a sediment deposition basin. The same flume was used in the previous preliminary experiments by Blanckaert et al. (2008) to investigate the influence of the bubble screen on the flow in a configuration with fixed horizontal bed.

Measurements will be reported in an orthogonal curvilinear $(s, n, z)$ reference system, with downstream $s$ axis along the flume's centerline, transverse $n$ axis pointing outward, and upward vertical $z$ axis. Quartz sand of nearly uniform diameter $1.6 \mathrm{~mm}<d<2.2 \mathrm{~mm}$ with a mean diameter of $2 \mathrm{~mm}$ was used as bed material. When conducting experiments with sediment feeding, the same sand was continuously introduced near the flume entrance.
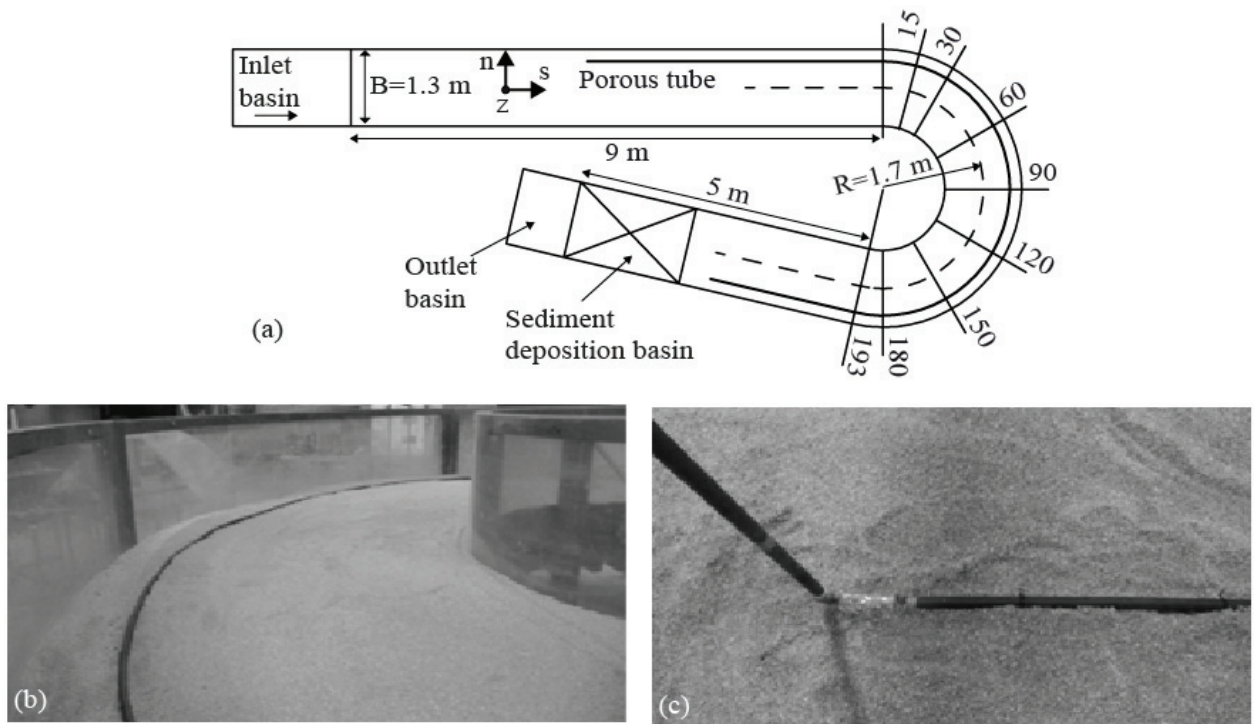

Fig. 1 (a) Plan view of the curved channel with the porous tube. (b) and (c) Porous tube with the connection to the pressurized air system existing at the two sides of the tube

A porous tube, with an inner diameter of $0.01 \mathrm{~m}$ (high-pressure tube of porous rubber, Multivis Waterbehandeling B.V.), placed on the bed of the flume generated the air-bubble screen. It was ballasted with a chain submerged in the sand to impede its movements, and connected at both ends to a pressurized air system to guarantee the same air pressure over the entire length of the tube (Figs. 1b, c). Microscopic holes in the tube were located on opposite sides of the diameter with a longitudinal spacing of $3 \mathrm{~mm}$. The size of the bubbles was estimated to vary between $0.002 \mathrm{~m}$ to 0.015 
$\mathrm{m}$, with an average diameter of about $0.005 \mathrm{~m}$. The air pressure was regulated with a manometer and the air discharge measured with a rotameter. An air discharge of $0.20910^{-3} \mathrm{~m}^{3} \mathrm{~s}^{-1}$ per unit length of porous tube was applied. For experiments with a bubble screen, the porous tube was placed at $0.2 \mathrm{~m}$ from the outer bank. The bubble screen extended from $5 \mathrm{~m}$ upstream of the bend entry to $2.5 \mathrm{~m}$ downstream of the bend exit.

\subsection{Velocity, water surface, and bathymetry measurements}

Flow was measured with an Acoustic Doppler Velocity Profiler (ADVP) developed at EPFL. This non-intrusive instrument measures the quasi-instantaneous velocity vector simultaneously along an entire water column. From this measurement, the mean velocity vector with its three components $\left(v_{s}, v_{n}, v_{z}\right)$ can be obtained. Moreover, the ADVP provides a measurement of the bed elevation. The working principle of the ADVP and its experimental uncertainty are reported in detail by Lemmin and Rolland (1997), Hurther and Lemmin (1998), Blanckaert and Lemmin (2006) and Blanckaert (2010). Detailed velocity measurements were only performed in the cross-section at $70^{\circ}$ in the bend, where the bar-pool morphology is most pronounced (Fig. 2). Because of interference of the air bubbles with the ADVP's acoustic signal, velocity measurements were not possible near the bubble screen. As a consequence, no velocities were measured between the porous tube and the outer bank.

The water surface was measured with a point gauge in the transverse positions $n=[-0.62,-0.6,-0.5,-0.3,-0.1,0.1$, $0.3,0.5,0.6,0.62]$ in 77 cross-sections situated between $5 \mathrm{~m}$ upstream of the bend in the straight inflow reach and 1.35 $\mathrm{m}$ downstream of the bend in the straight outflow reach. The bed morphology was measured with a laser distometer on a refined grid with a transverse spacing of $5 \mathrm{~cm}$, from $4 \mathrm{~m}$ upstream of the bend to $2 \mathrm{~m}$ downstream of the bend, and a longitudinal spacing of $5^{\circ}$ in the bend.

\subsection{Experimental conditions}

Three experiments were performed under different conditions of sediment supply and bubble generation, but with similar hydraulic conditions in order to facilitate comparison. Experimental conditions are listed in Table 1. The LB_NB experiment was performed under live-bed conditions with a constant rate of sediment feeding at the entrance of the flume, but without bubble screen; the CW_NB experiment was performed under clear-water scour conditions without bubble screen and the CW B experiment was performed under clear-water scour conditions with bubble screen. In the labels, LB stands for live-bed, CW for clear-water scour, NB for no bubble screen, and B for bubble screen. In all experiments, the initial condition was a flat bed.

All experiments were performed until morphological equilibrium was reached. Under live-bed conditions, equilibrium was reached when: (i) the rate of sediment fed to the flume equaled the rate of sediment deposited in the downstream basin, (ii) the bed morphology remained stable, with the exception of migrating mesoscale bedforms. Under clear-water scour conditions, it is well known that the temporal development of the bed morphology is asymptotic, with a fast initial development that subsequently continuously slows down, to become ultimately infinitesimally slow. Roca et al. (2007, their Fig. 7) illustrated this for bend scour, and Masjedi et al. (2010) for bridge pier scour. The clear-water scour experiments were performed until all sediment transport vanished and the remaining evolution became infinitesimally slow.

The migration of mesoscale bedforms at equilibrium in the live-bed experiment complicated the velocity measurements: bedforms migrated over a substantial distance during the time required to measure one cross-section, resulting in significant modifications in the flow patterns. In order to circumvent this problem and to allow for detailed ADVP measurements, the bed morphology was frozen by spraying paint on it, and the sediment feeding was stopped. In the clear-water scour experiment, sediment transport had vanished at equilibrium and the mesoscale bedforms remained stationary. Therefore, no freezing of the bed was required to allow for detailed ADVP velocity measurements. This comparable easy in execution was the primary motivation for performing the experiment with bubble screen under clear-water scour conditions. The LB_NB and CW_NB experiments without bubble screen were first performed in order to verify that similar dominant features of the morphology and flow field develop under live-bed and clear-water scour conditions.

\section{Results}

\subsection{Influence of the bubble screen on the bed morphology}

Figure 2 illustrates the morphology in the three experiments. The flume-averaged bed level defines the reference level, $z=0 \mathrm{~m}$. The live-bed (LB NB) and clear-water scour (CW NB) experiments without bubble screen are characterized by similar morphological features that are typical for sharply curved open-channel bends (Roca et al., 2007; Blanckaert, 2010): a bar-pool morphology with two deep scour holes located near the entry and the exit of the bend, respectively, and a depositional bar at the inner bank between the cross sections located at $30^{\circ}$ and $150^{\circ}$ in the bend. The maximum scour depth in both experiments is similar and about $0.25 \mathrm{~m}$ under the flume-averaged bed level. These similar morphological features lend credit to the experiments performed under clear-water scour conditions. 

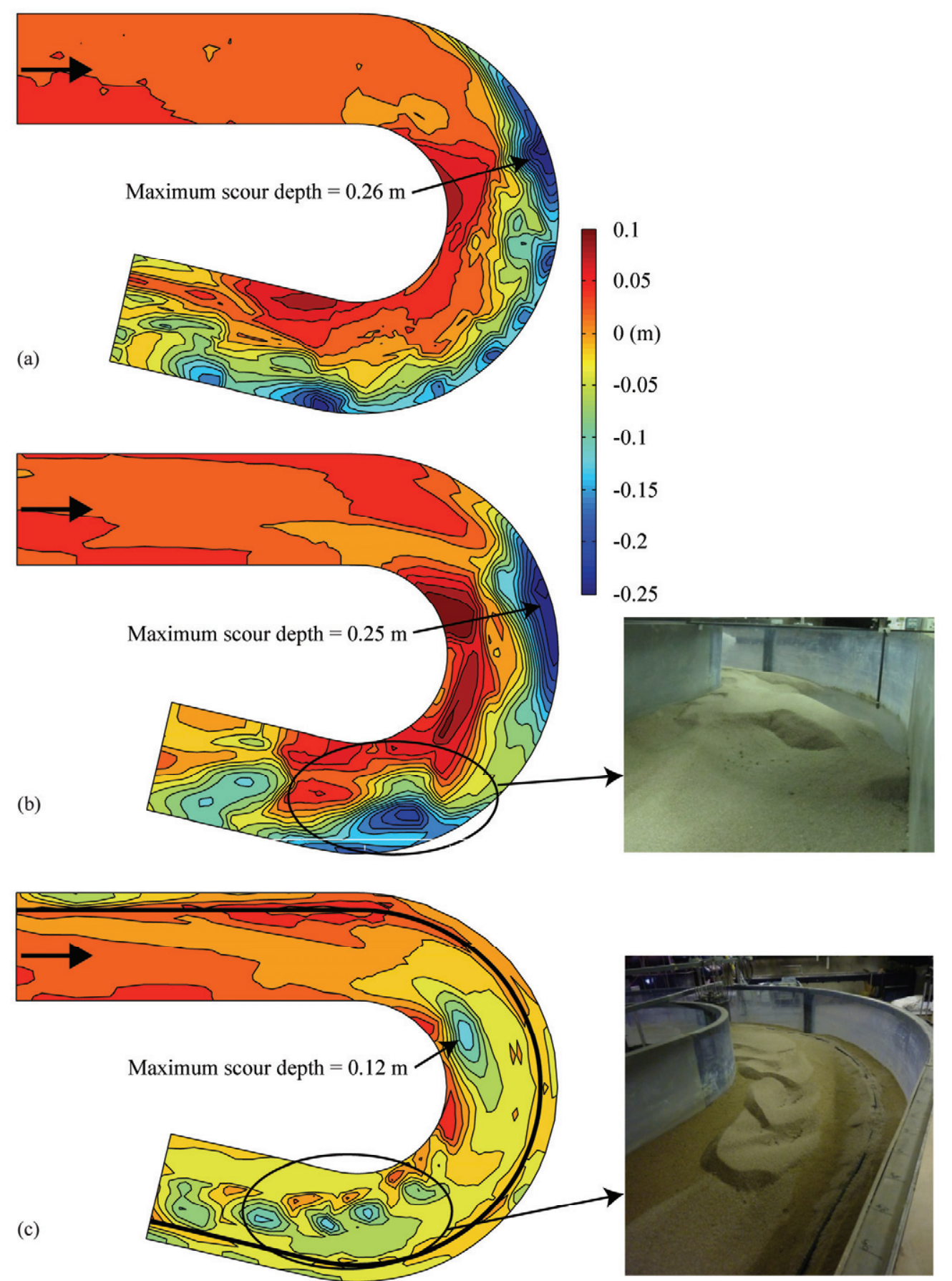

Fig. 2 Isolines of the bed level with an interval of $0.02 \mathrm{~m}$ derived from laser distometer measurements for the LB_NB (a), CW_NB (b) and CW_B (c) experiments. The same color scale has been used to facilitate comparison. The inserted pictures on the right provide visualization of the mesoscopic bedform features in the downstream part of the bend

Table 1 Experimental conditions. $Q$ is the water discharge, $q_{s}$ is the sediment discharge, $P a$ is the chosen air- pressure, $H$ is the final flume-averaged flow depth, $U=Q / B H$ is the flume-averaged velocity, $S$ is the flume-averaged water slope. The first part of the experiments' labels signifies live-bed (LB) or clear-water scour (CW) conditions, and the second part experiments without (NB) or with (B) the bubble screen

\begin{tabular}{|c|c|c|c|c|c|c|c|c|c|}
\hline & $Q$ & $q_{s}$ & $P a$ & $H$ & $U$ & $S$ & $R / B$ & $R / H$ & $B / H$ \\
\hline Label & $l s^{-1}$ & $K g\left(\mathrm{~ms}^{-1}\right)$ & $k P a$ & $m$ & $m s^{-1}$ & $10^{-4}$ & - & - & - \\
\hline LB_NB & 63 & 0.023 & - & 0.10 & 0.49 & 28 & 1.31 & 17.2 & 13.2 \\
\hline CW_NB & 57 & - & - & 0.14 & 0.31 & 7.36 & 1.31 & 11.9 & 9.1 \\
\hline CW_B & 55 & - & 500 & 0.14 & 0.31 & 1.61 & 1.31 & 12.2 & 9.3 \\
\hline
\end{tabular}


The bubble screen in the CW_B experiment considerably attenuates morphological gradients: the bed level is in general much flatter than in the experiments without bubble screen due to reduced scour and deposition. The maximum scour depth is reduced by about $50 \%$ to $0.12 \mathrm{~m}$ and its location is shifted away from the outer bank towards the center of the flume, where it does not endanger bank stability anymore. The depositional bar at the inner bank has almost vanished, and does not noticeably reduce the navigable width anymore.

Figure 3a reports the streamwise evolution of the transverse bed slope (determined by linear fitting) in the three experiments. In both experiments without bubble screen, the transverse bed slope shows pronounced streamwise variations and reaches considerable maximum values in both scour holes. The bubble screen considerably attenuates the maximum transverse bed slope and its streamwise variations. Figure $3 \mathrm{~b}$ further substantiates the pronounced morphological modification induced by the bubble screen in the cross-section at $70^{\circ}$ in the bend for the three experiments.
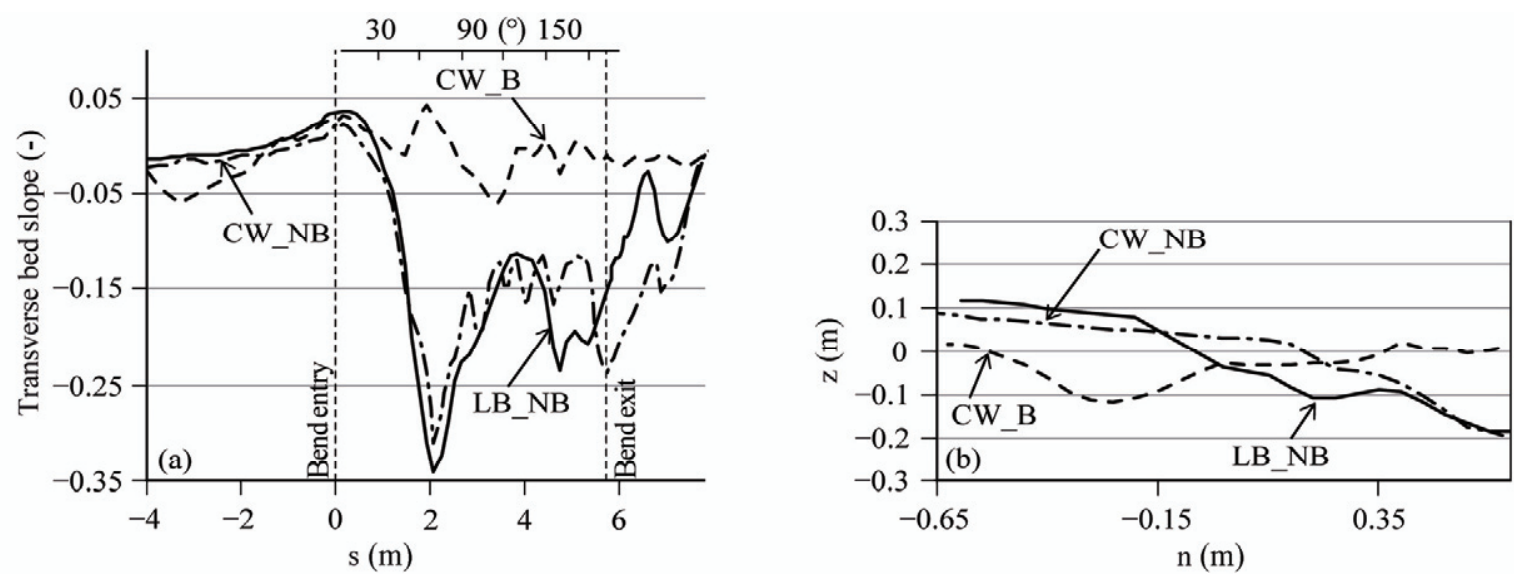

Fig. 3 Streamwise evolution of the transverse bed slope (a) and bed elevations in the cross-section at $70^{\circ}$ in the bend (b). Comparison of the live bed experiment without bubble screen (LB_NB), the clear-water scour experiment without bubble screen (CW_NB) and the clear-water scour experiment with bubble screen (CW B). The streamwise distance from the bend entry is indicated by $s$, the transverse distance from the centerline by $n$, and the elevation over the flume-averaged bed level by $z$.

In the clear-water scour experiment with bubble screen (CW_B), no sediment transport is observed in the outer-part of the cross-section and the bed remains nearly flat at its initial level. Without bubble screen, bend effects cause a substantial increase of the velocities and bed shear stress in this zone that leads to the formation of the maximum bend scour. These results indicate the efficiency of the bubble screen to counteract the curvature-induced increase in velocities and bed shear stresses in this zone.

Mesoscale bedforms occur in all experiments (see photos inserted in Fig. 2). In the clear-water scour experiment without bubble screen (CW_NB), large amplitude dunes can be discerned in the downstream part of the bend. In the clear-water scour experiment with bubble screen (CW_B), dunes have smaller wavelength and amplitude. The inwards shift of the location of the dunes is reminiscent of the inwards shift of the location of the core of maximum streamwise velocities.

\subsection{Influence of the bubble screen on the velocity redistribution}

In order to explain how the bubble screen redistributes the morphology and the flow, the present section investigates its influence on the flow field. Figures 4, 5 and 6 report patterns of the three velocity components (streamwise, transverse and vertical), as well as the profiles of the water surface and bed elevations, in the cross-section at $70^{\circ}$ in the bend for the LB_NB and CW_B experiments. Flow patterns in the CW_NB experiment (not shown) are similar to those in the LB_NB experiment, which further lends credit to the experiments performed under clear-water scour conditions. In the LB_NB experiment, the depth near the inner bank was too shallow to measure with the ADVP. In the CW B experiment, the velocities in the vicinity of the bubble screen could not be measured because of interference between the bubbles and the ADVP signal.

In the reference LB_NB experiment without bubble screen, the flow patterns typical of open-channel bends are observed (Blanckaert, 2011): curvature-induced secondary flow is constrained to the deepest part of the cross-section with transverse velocities toward the outer bank at the surface and toward the inner bank at the bed, and vertical velocities impinging on the bed close to the outer bank (Fig. 4a and Fig. 5b,c). In the CW_B experiment with bubble screen, the curvature-induced secondary flow is weakened (Fig. 5b,c vs. Fig. 6b,c) and an additional bubble-induced counter-rotating secondary flow exists near the outer bank (Fig. $4 \mathrm{~b}$ and Fig. $5 \mathrm{~b}, \mathrm{c}$ ), with a transverse extent from about $n$ 
$=-0.2 \mathrm{~m}$ to about $n=0.45 \mathrm{~m}$ (position of the porous tube). The core of maximum vertical velocities impinging on the bed defines the limit of the two secondary flows. This core about coincides with the location of maximum scour, which indicates the important role it plays with respect to the development of bend scour. These vertical velocities impinging on the bed are due to the combined effect of the two counter-rotating secondary flows. Their amplitudes, however, are smaller than the ones observed near the outer bank in the reference LB_NB experiment, which could partially explain the observed reduction in the maximum scour depth.
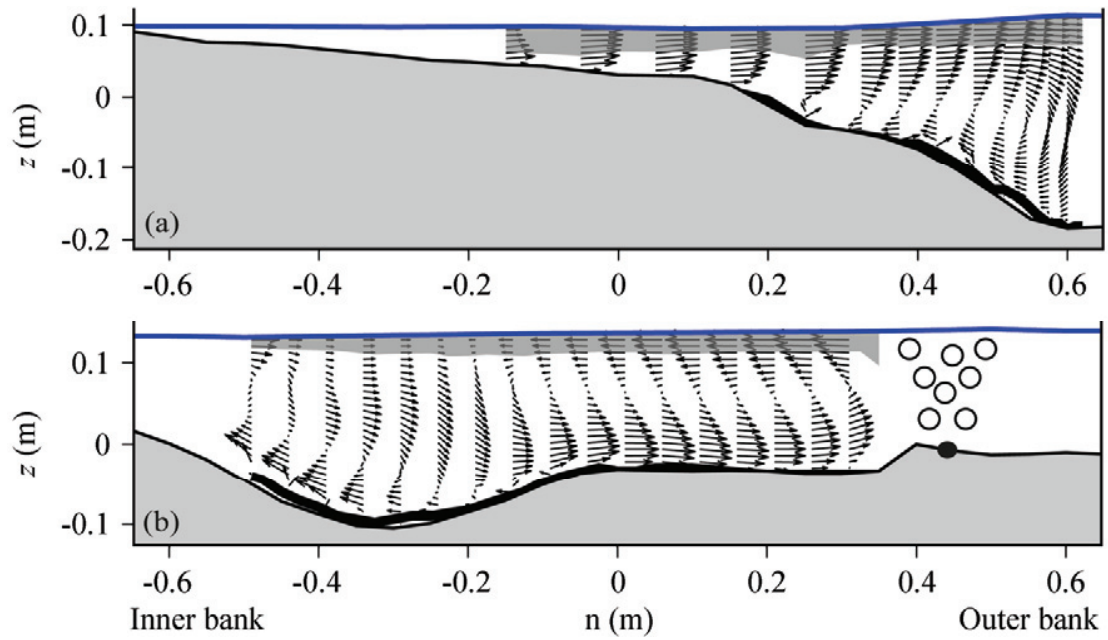

Fig. 4 Patterns of normalized secondary flow $\left(v_{n}, v_{z}\right) / U$. Measurements performed in the cross-section at $70^{\circ}$ in the bend (a) for the live-bed experiment without bubble screen (LB_NB) and (b) for the clear-water scour experiment with bubble screen (CW B). Bed elevation estimated from ADVP measurements (thick black line) and from laser distometer measurements (thin black line). The shaded area near the water surface indicates extrapolated values. $U=Q /(B H)$ is the flume-averaged velocity. The transverse distance from the centerline is indicated by $n$, and the elevation over the flume-averaged bed level by $z$.
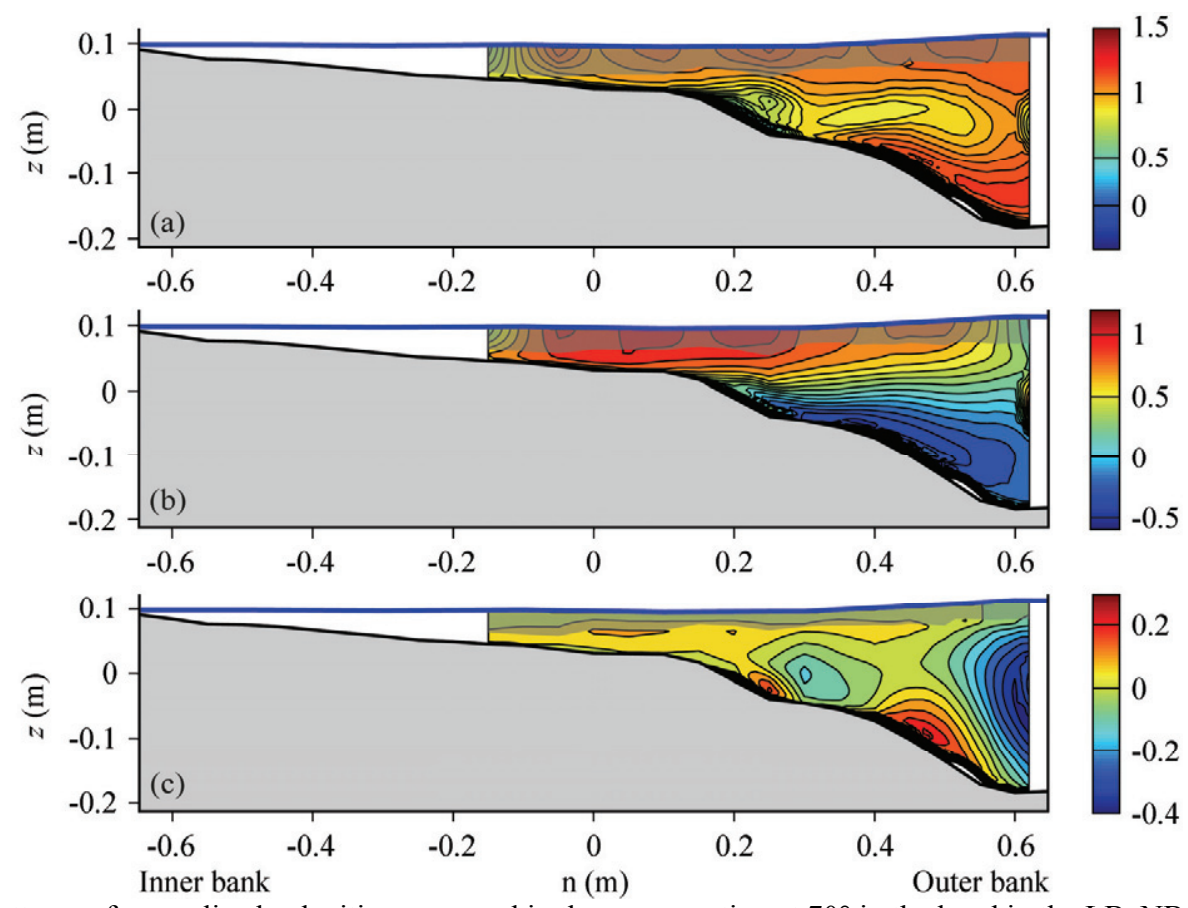

Fig. 5 Patterns of normalized velocities measured in the cross-section at $70^{\circ}$ in the bend in the LB_NB live-bed experiment without bubble screen. (a) Streamwise velocity $v_{s} / U$, (b) transverse velocity $v_{n} / U$, and (c) vertical velocity $v_{z} / U$. Bed elevation estimated from ADVP measurements (thick black line) and from laser distometer measurements (thin black line). The shaded area near the water surface indicates extrapolated values. The transverse distance from the centerline is indicated by $n$, and the elevation over the flume-averaged bed level by $z$. 

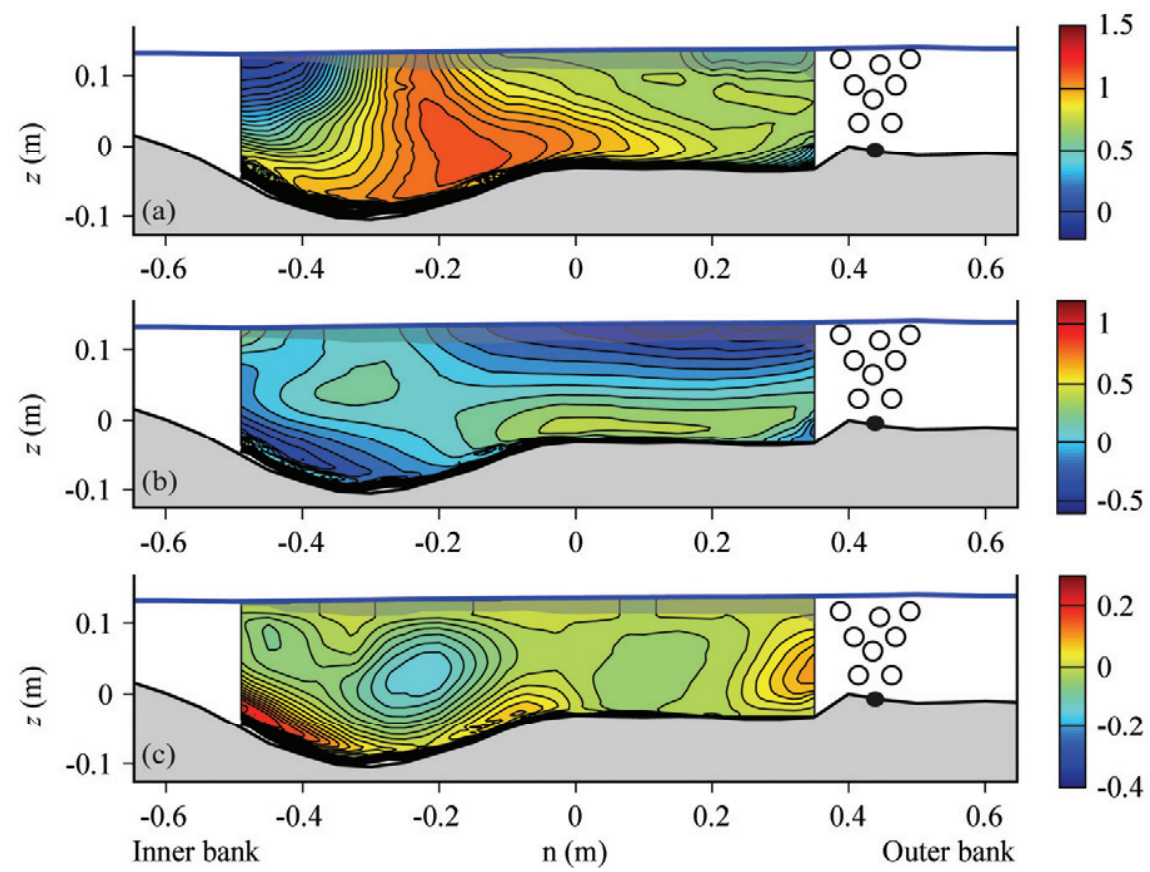

Fig. 6 Patterns of normalized velocities measured in the cross-section at $70^{\circ}$ in the bend in the CW_B clear-water scour experiment with bubble screen. (a) Streamwise velocity $v_{s} / U$, (b) transverse velocity $v_{n} / U$, and (c) vertical velocity $v_{z} / U$. Bed elevation estimated from ADVP measurements (thick black line) and from laser distometer measurements (thin black line). The shaded area near the water surface indicates extrapolated values. The transverse distance from the centerline is indicated by $n$, and the elevation over the flume-averaged bed level by $z$.

Secondary flow is known to be efficient in redistributing velocities (Blanckaert and de Vriend, 2003; Blanckaert and Graf, 2004). This is confirmed by the patterns of the streamwise velocity in both experiments. In the LB_NB experiment without bubble screen, the curvature-induced secondary flow (Fig. 4a) advects high near-surface velocities in outward direction and towards the toe of the outer bank. As a result, the core of largest streamwise velocities $v_{s}$ occurs near the toe of the outer bank (Fig. 5a), where it promotes bend scour and enhances the flow attack on the bank. In the CW_B experiment with bubble screen, advective redistribution by both secondary flows causes the core of maximum streamwise velocities to occur at the junction between both secondary flows, where the maximum scour occurs (Fig. 6a). Velocities near the bed in the core of maximum streamwise velocities are weaker in the experiment with bubble screen, which could partially explain the observed reduction in maximum scour depth.

\section{Discussion}

The reported laboratory experiments convincingly demonstrate that the bubble-screen technique has the potential to become a useful tool for redistributing the flow patterns and the morphology in open-channel bends, and for mitigating bend scour. Its mechanism is schematically represented in Fig. 7. The bubble screen generates a bubble-induced secondary flow with a sense of rotation opposite to the curvature-induced one. This additional secondary flow redistributes the velocity patterns and shifts the cores of maximum streamwise and downward velocities away from the outer bank, toward the junction between the two secondary flow cells. Consequently, the zone of maximal scouring is also shifted away from the outer bank toward the junction of the two secondary flow cells.

Hereafter, some further issues that need to be investigated in the process of developing the bubble-screen technique into a tool that is applicable in real world situations are discussed:

(i) The bubble-screen technique essentially consists in counteracting the curvature-induced secondary flow. Hence, its efficiency can be assumed to depend on the relative strengths of the bubble-induced and curvature-induced secondary flows. The strength of the bubble-induced secondary flow probably varies in a relatively narrow range. Comparison of experiments with the bubble screen in straight and curved flow configurations suggests that it is only weakly influenced by the degree of bend curvature (Blanckaert et al., 2008). Moreover, the rising velocity of air bubbles is known to be about constant at $0.24 \mathrm{~ms}^{-1}$ in the range of applied bubble sizes (Leifer et al., 2000). Therefore, the bubble screen can be assumed to induce comparable secondary-flow velocities in laboratory flumes and real world rivers. The curvature-induced secondary flow is known to depend on numerous parameters, including the river planform (degree of curvature and its streamwise evolution, river geometry and width), the flow characteristics (velocity of the mean flow, boundary roughness) and the scale of the river (flow depth). In first approximation, the curvature-induced secondary-flow velocities scale with the parameter $U H / R$ (Rozovskii, 1957; Engelund, 1974). Based on this scaling argument, Blanckaert et al. (2008) have shown that the bubble-induced secondary-flow velocities are of comparable International Journal of Sediment Research, Vol. 28, No. 1, 2013, pp. 15-23 
magnitude as the curvature-induced secondary-flow velocities in large natural rivers. The scaling argument further suggests that the bubble-screen technique's efficiency will decrease when the river's control parameter $U H / R$ increases. Hence it can be assumed to be most efficient in mildly and moderately curved rivers, with gradual variations in curvature, and a flow characterized by a low Froude number $\left(F r=U /(g H)^{1 / 2}\right)$.
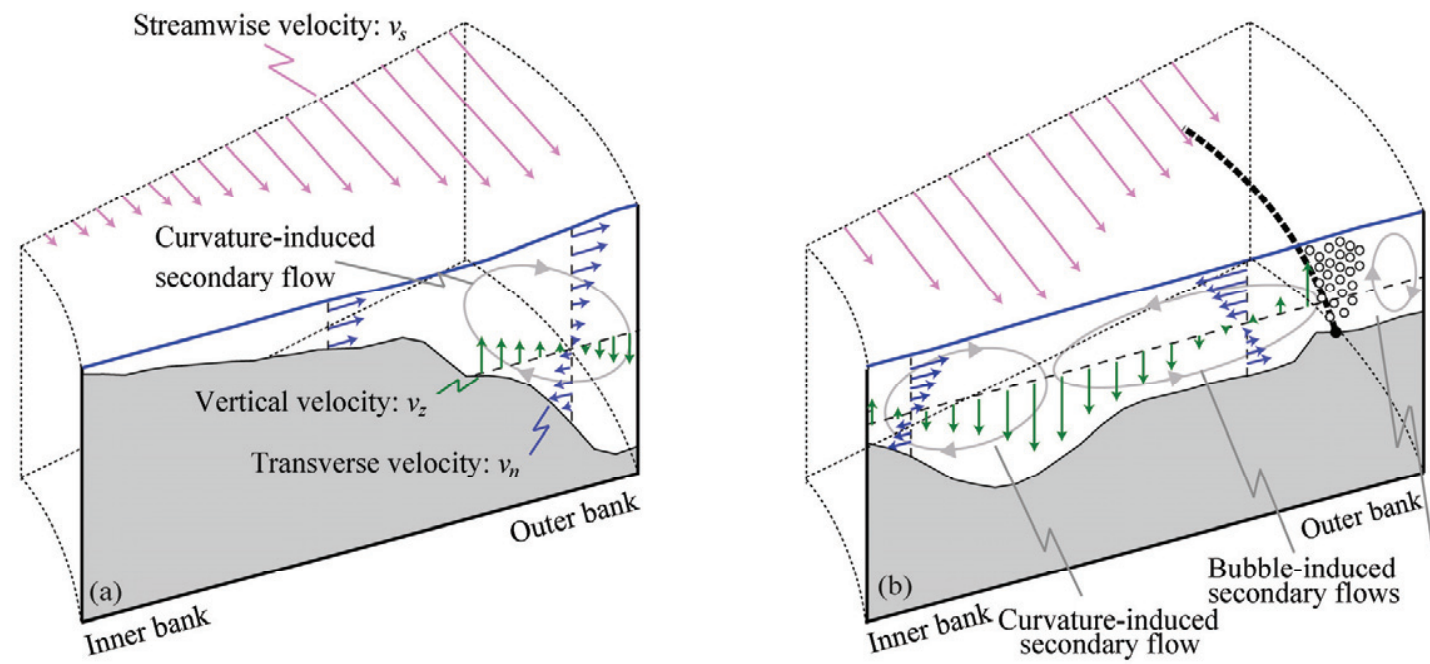

Fig. 7 Mechanism of the bubble-screen technique deduced from the experimental results. Schematic representation of the flow and the morphology in a configuration without bubble screen (a) and with bubble screen (b)

(ii) The efficiency of the bubble-screen technique will also depend on the intensity of the flow-sediment interactions, which is determined by e.g., the sediment characteristics (mean diameter and standard deviation), the sediment transport rate, and the occurrence of sediment transport in suspension. The here reported experiment with bubble screen was performed under conditions of clear-water scour, which is a mobile-bed configuration where sediment transport vanishes at equilibrium. Due to the highly nonlinear character of the flow-bed interactions, their influence is not straightforward to infer based on scaling arguments and the behavior under live-bed conditions cannot be anticipated.

(iii) The efficiency of the bubble-screen technique will obviously also depend on the air flux and on the transversal position of the porous tube on the river bed.

(iv) Potential adverse impacts of the bubble screen also need to be investigated. First, the bubble screen obviously modifies the flow field in the region between the bubble screen and the outer bank, where no measurements could be made in the here reported experiment. It is important to investigate the influence of the bubble screen on the flow forcing on the outer bank, as well as its dependence on the outer-bank configuration (slope and roughness of the bank). Second, the air bubbles in the water can decrease the density of the air-water mixture, and hence reduce the buoyancy of ships. It is important to quantify this buoyancy reduction in applications of the bubble-screen technique that aim at enlarging the navigable width of the river.

Additional experiments are required to quantify the influence of the dominant control parameters and of the sediment transport under live-bed conditions, to optimize the bubble screen's air flux and positioning, and to investigate adverse impacts. These additional experiments will provide enhanced insight in the processes involved and allow for a more accurate delimitation of the application range of the bubble-screen technique.

Further research also needs to focus on the application of the bubble-screen technique in other river configurations. The bubble-screen technique may be particularly appropriate to reduce local scour around structures (bridge piers, abutments, etc). This local scour, provoked by vertical velocities impinging on the river bed, could be counteracted by the rising air bubbles.

\section{Conclusions}

Open-channel bends are characterized by a strong interplay between streamwise velocities, curvature-induced secondary flow, sediment transport and bed morphology. Maximum scour is typically found near the outer bank, and attributed to the maximum streamwise velocities that occur near the toe of the bank and the maximum vertical secondary-flow velocities that impinge on the bed near the toe of the bank.

The presence of a bubble screen near the outer bank, with its rising vertical velocities, generates an additional secondary flow located between the outer bank and the curvature-induced secondary flow, and with a sense of rotation opposite to the latter. The bubble screen shifts the cores of maximum streamwise velocities and maximum vertical velocities impinging on the bed away from the outer bank, to a distance where they do not endanger bank stability anymore. Both these flow characteristics play an important role in the development of bend scour, as indicated by their coincidence with the location of maximum bend scour. This location further coincides with the junction of the 
curvature-induced and bubble-induced secondary flows, which indicates the dominant role played by the bubbleinduced secondary flow in the modification of the morphology and flow patterns. The bubble screen causes a considerable attenuation of the morphological gradients. The maximum bend scour is reduced by about $50 \%$, and the inner bank deposition bar has almost vanished, resulting in less shallow flow.

The reported results from laboratory experiments clearly demonstrate the potential of the bubble screen technique to modify the morphology in open-channel bends. The paper discusses further steps that are required to develop this bubble-screen technique into a tool that is applicable in natural rivers.

\section{Acknowledgements}

This research was financially supported by the Swiss National Science Foundation under grants 200021-125095. Professor C.D. Rennie is acknowledged for his constructive comments and suggestions. The second author was partially funded by the Chinese Academy of Sciences Visiting Professorship for Senior International Scientists, grant number 2011T2Z24, and by the Sino-Swiss Science and Technology Cooperation for the Institutional Partnership Project, grant number IP13_092911.

\section{References}

Blanckaert K. 2010, Topographic steering, flow recirculation, velocity distribution, and bed topography in sharp meander bends. Water Resources Research, Vol. 46, W09506, doi:10.1029/2009WR008303.

Blanckaert K. 2011, Hydrodynamic processes in sharp meander bends and their morphological implications. Journal of Geophysical Research - Earth Surface, Vol. 116, F01003, doi:10.1029/2010JF001806.

Blanckaert K. and de Vriend H. J. 2003, Nonlinear modeling of mean flow redistribution in curved open-channels. Water Resources Research, Vol. 39, No. 12, pp. 1375-1381.

Blanckaert K. and de Vriend H. J. 2004, Secondary flow in sharp open-channel bends. Journal of Fluid Mechanics, Vol. 498, No. 1, pp. 353-380.

Blanckaert K. and de Vriend H. J. 2010, Meander dynamics: A nonlinear model without curvature restrictions for flow in open-channel bends. Journal of Geophysical Research - Earth Surface, Vol. 115, F04011, doi: 10.1029/2009JF001301.

Blanckaert K. and Graf W. H. 2004, Momentum transport in sharp open-channel bends. Journal of Hydraulic Engineering, Vol. 130, No. 3, pp. 186-198.

Blanckaert K. and Lemmin U. 2006, Means of noise reduction in acoustic turbulence measurements. Journal of Hydraulic Research, Vol. 44, No. 1, pp. 3-17.

Blanckaert K., Buschman F. A., Schielen R., and Wijbenga J. H. A. 2008, Redistribution of velocity and bed-shear stress in straight and curved open-channels by means of a bubble screen: Laboratory experiments. Journal of Hydraulic Engineering-ASCE, Vol. 134, No. 2, pp. 184-195.

Engelund F. 1974, Flow and bed topography in channel bends, Journal of the Hydraulics Division, Vol. 100, No. HY11, pp. $1631-1648$.

Hurther D. and Lemmin U. 1998, A constant-beam-width transducer for 3D acoustic Doppler profile measurements in open-channel flows. Measurement Science and Technology, Vol. 9, No. 10, pp. 1706-1714.

Leifer I., Patro R. K., and Bowyer P. 2000, A study on the temperature variation of rise velocity for large clean bubbles. Journal of Atmospheric and Oceanic Technology, Vol. 17, No. 10, pp. 1392-1402.

Lemmin U. and Rolland T. 1997, Acoustic velocity profiler for laboratory and field studies. Journal of Hydraulic Engineering-ASCE, Vol. 123, No. 12, pp. 1089-1098.

Masjedi A., Bejestan M. S., and Esfandi A. 2010, Experimental study on local scour around single oblong pier fitted with a collar in a 180 degree flume bend. International Journal of Sediment Research, Vol. 25, No. 3, pp. 304-312.

Odgaard A. J. and Spoljaric A. 1986, Sediment control by submerged vanes. Journal of Hydraulic Engineering-ASCE, Vol. 112, No. 12, pp. $1164-1181$.

Odgaard A. J. and Wang Y. 1991, Sediment management with submerged vanes. 1. Theory. Journal of Hydraulic Engineering-ASCE, Vol. 117, No. 3, pp. 267-283.

Przedwojski B. 1995, Bed topography and local scour in rivers with banks protected by groynes. Journal of Hydraulic Research, Vol. 33, No. 2, pp. 257-273.

Roca M., Martin-Vide J. P., and Blanckaert K. 2007, Reduction of bend scour by an outer bank footing: Footing design and bed topography. Journal of Hydraulic Engineering-ASCE, Vol. 133, No. 2, pp. 139-147.

Rozovskii I. L. 1957, Flow and water in bends of open channels. Academy of Sciences of the Ukrainian SSr, Isr. Progr. Sc. Transl., Jerusalem, Israel.

Schladow S. G. 1992, Bubble plume dynamics in a stratified medium and the implications for water quality amelioration in lakes. Water Resources Research, Vol. 28, No. 2, pp. 313-321.

Smith B. L. 1998, On the modelling of bubble plumes in a liquid pool. Applied Mathematical Modelling, Vol. 22, No. 10, pp. $773-797$.

Teraguchi H., Nakagawa H., Kawaike K., Baba Y., and Zhang H. 2011, Effects of hydraulic structures on river morphological processes. International Journal of Sediment Research, Vol. 26, No. 3, pp. 283-303.

Wüest A., Brooks N. H., and Imboden D. M. 1992, Bubble plume modeling for lake restoration. Water Resources Research, Vol. 28, No. 12 , pp. 3235-3250. 